\title{
Restructuring of the regional investment and construction complex
}

\author{
Ludmila Kaverzina ${ }^{1, *}$ \\ ${ }^{1}$ Bratsk State University, 665709, Makarenko str., 40, Bratsk, Russia
}

\begin{abstract}
The relevance of the study is conditioned by the need for structural reforms in the regional investment and construction complex, caused by the transition of the Russian economy to an innovative way of development. The purpose of this study is to improve the mechanism for restructuring of the regional investment and construction complex, and to develop a step-by-step model for its implementation. Based on the analysis of the state of the regional investment and construction complex, factors that adversely impact the efficiency of innovation processes in the regional economy and issues that hamper development of the regional investment and construction complex are revealed. A mechanism for restructuring of the regional investment and construction complex has been developed, which includes five interrelated elements: target functions, links of the mechanism, and normative, strategic and operational subsystems that allow reflecting the transformations implemented in the regional economy as a whole, and in the investment and construction complex of the region in particular. A step-by-step model for the restructuring of the regional investment construction complex is proposed, the practical use of which will improve the performance of the investment and construction complex, the enterprises that make up its structure, as well as the indicators of the region's economic development as a whole. A system of equations is proposed, with the help of which it is possible to describe changes in interaction with the economy of a particular region in the regional investment and construction complex and the enterprises that make it up. In the work, methods of systemic analysis and tools of mathematical statistics and economic and mathematical modeling have been used.
\end{abstract}

\section{Introduction}

Today the Russian economy is developing on the priority innovative principles in accordance with the Strategy of innovative development of the Russian Federation approved in 2011 for the period up to 2020. Successful implementation of the elaborated Strategy requires systematic reform of the economy of particular regions. The development of regional economy to a major extent depends on the results of activities and the possibilities of development of the investment and construction complex (ICC), since a material base that is so necessary for the successful operation of any enterprise operating in the region is created by the construction industry. It is the state of the investment and

\footnotetext{
*Corresponding author: dekanfps@ mail.ru
} 
construction complex that significantly affects the pace of development of regional economy, contributing to the planned allocation of the productive forces. Reforming regional economy and carrying out structural reforms in the investment and construction complex is one of the initial conditions for the transition to the innovative way of development. In this connection, the issues considered within the framework of this article acquire a special relevance.

The problems related to the functioning of the investment and construction complex and its constituent enterprises have been addressed by many domestic economists. Thus, the issues of managing the ICC are covered in the works of V.V. Buzyrev, S.N. Strizhkov, N.A. Samarskaia, A.M. Platonov, S.Yu. Pleshkov, G.V. Khomkalov, E.I. Kelberg, E.B. Smirnov, S.Yu. Vetlugin, Yu.P. Panibratov, V.L. Tsapu [1-6]. The works of V.V. Buzyrev, I.V. Fedoseyev, A.D. Kot, N.V. Chepachenko, V.A. Dmitriev, L.A. Kaverzina, I.I. Mazur, V.D. Shapiro, S.A. Titov, L.V. Elkina, M.S. Motyshina, M.B. Sokolovskaya [7, 8, 9, 10, 11] are devoted to the improvement of theoretical and methodological background of restructuring and solving the issues of its practical implementation, including the investment and construction sphere. Investment and construction activity has its own peculiarities and always involves certain difficulties and problems, which are studied by A.N. Asaul, Yu.P. Panibratov, V.I. Pasyada, V.V. Peshkov, M.V. Aristova, E.B. Smirnov, and K.S. Evtukova [12, 13, 14, 15, 16].

Generalization of the materials presented in the works of the above-mentioned authors, as well as the analysis of the results of restructuring in different socio-economic systems, make it possible to assert that further development of the theoretical and methodological basis of structural transformations in the regional economy is required, and special attention should be paid to the investment and construction complex. For the development of the territories of our country, additional research and intensification of innovative activity in construction are required $[17,18]$. The most thorough attention should be paid to the environmental and economic aspects of investment and construction activities in the regions $[19,20]$. It is necessary to work towards the development of effective organizational and economic restructuring mechanisms on the basis of clearly formulated methodological aspects of its implementation. The process of managing regional investment and construction complex when carrying out its restructuring also requires further improvement [9].

Insufficient elaboration of the above-mentioned issues justified the purpose of this study: the improvement of mechanism of the regional ICI restructuring and the development of a step-by-step model for restructuring, while the organizational and economic relations implemented by the actors of the regional investment and construction complex in the process of its functioning and restructuring is the subject of the research.

\section{Materials and methods of the study}

In the process of work on the issues formulated in the paper, methods of the system analysis, economic-mathematical modeling, and tools of mathematical statistics have been used.

In course of the research, information and statistical materials on the activities of federal and territorial authorities engaged in management of the investment and construction complex, data of the Territorial Body of the Federal State Statistics Service for the Irkutsk Region have been utilized.

The application of methods of processing statistical information made it possible to assess the state of the ICI of the Irkutsk region, as a result of which factors that adversely impacted the effectiveness of innovation processes in the region have been identified. Among such factors are the following: the imperfection of the legislative framework for 
regulating innovation activity, the constant shortage of own current assets experienced by micro-level businesses, the complexity of lending to innovative business ideas and the implementation of investment projects. Some obstacles that hampered the development of the regional ICC have been found out, namely: high depreciation rates of the fixed assets in construction, inadequate implementation of innovative projects in the construction sector of the region, problems connected with staffing and disruptions in the rhythm of the enterprises that make up the ICC of the Irkutsk region, and limited solvency of consumers of construction products.

Successful solution of these issues can be based on the structural changes in the regional investment and construction complex through its restructuring.

The author developed a mechanism for the regional ICC restructuring, which includes five interrelated elements: target functions; links of the mechanism; normative, strategic and operational subsystems. This mechanism reflects the changes that are to be implemented in the regional economy in general, and in the investment and construction complex of the region in particular. The developed mechanism influences certain elements of the regional ICC, including the principles of its organizational structure and the organizational structures of the subjects, management subsystems and organizational processes.

The methodological provisions of the proposed organizational mechanism for restructuring of the regional investment and construction complex and the procedure for implementing the changes occurring therein when implementing this mechanism have been developed on the basis of analysis of theories on the organizational structures and dynamics of changes in the regional ICC, as well as the complex and systemic approaches to the management structures of different levels (micro-, meso- and macro-level).

In the framework of the proposed mechanism, a step-by-step model for restructuring of the regional investment construction complex has been elaborated (Figure 1). The use of this model in carrying out structural changes in the construction sphere will improve the performance of the ICC and enterprises that make up its structure, as well as indicators of the region's economic development as a whole.

In course of the research, the methods of economic and mathematical modeling have also been used. The region, its investment and construction complex and the enterprises that make up the ICC have been chosen as the objects of modeling. Using the method of system dynamics, based on the developed systems of equations, it is possible to describe the changes in the parameters of the regional ICI activity, as well as of the enterprises that make up its structure, occurring in time, in interaction with the economy of a particular region.

As a result, systems of equations have been developed in a vector form, with the help of which it is possible to describe the changes occurring in the modeling objects, also when carrying out structural transformations:

a) For the region:

$$
\frac{d \Pi C_{p}}{d t}=A_{p}\left(a, \Pi C_{p}\right)+D_{p}\left(\sigma, Y_{p}\right),
$$

b) For the regional ICC as a whole:

$$
\frac{d \Pi C_{И С K}}{d t}=A_{И С К}\left(a, \Pi C_{И С K}\right)+Б_{И С K}\left(\sigma, Y_{И С К}\right)
$$

c) For the companies that make up the ICC: 


$$
\frac{d \Pi C_{n}}{d t}=A_{n}\left(a, \Pi C_{n}\right)+b_{n}\left(\sigma, Y_{n}\right)
$$

where $\Pi C_{n}, \Pi C_{И С К}, \Pi C_{p}$ - vectors of parameters, reflecting condition of different modelling objects (a region, regional ICC and particular enterprises), respectively;

$A_{n}\left(a, \Pi C_{n}\right), A_{И C K}\left(a, \Pi C_{И С K}\right), A_{p}\left(a, \Pi C_{p}\right)$ - the vectors of functions, that establish the interaction of various processes occurring within particular enterprises that make up ICC, regional ICI in general and within the region, respectively;

$Б_{n}\left(\sigma, Y_{n}\right), \quad Б_{\text {ИСК }}\left(\sigma, Y_{\text {ИСК }}\right), \quad{ }_{p}\left(\sigma, Y_{p}\right)$ - vector functions characterizing interaction of processes on the enterprises of the ICC, in the ICC itself and in the region, connected with the management vector functions $Y_{n}, Y_{И С К}, Y_{p}$;

$a, \sigma$ - coefficients depending on the structure of the systems under consideration (the enterprises of the ICC, in the ICC itself and in the region) and, that are, in a general case, the given functions of time $t$.

Reflection of the processes occurring at the modeling objects considered in this paper can be realized by developing a multi-level system of models, the practical implementation of which can be represented in the form of a structural model that looks like:

$$
M_{n}\left\{M_{n 1}, M_{n 2}, \ldots, M_{n m}\right\}
$$

Local structural models (M1, M2, M3, etc.) are the constituents of the structural model, reflecting certain moments of the ICC functioning, taking into account existing external and internal interrelations (development of capital investments in the region, existing links between the ICC components, etc.). A more detailed description of them is given in [9].

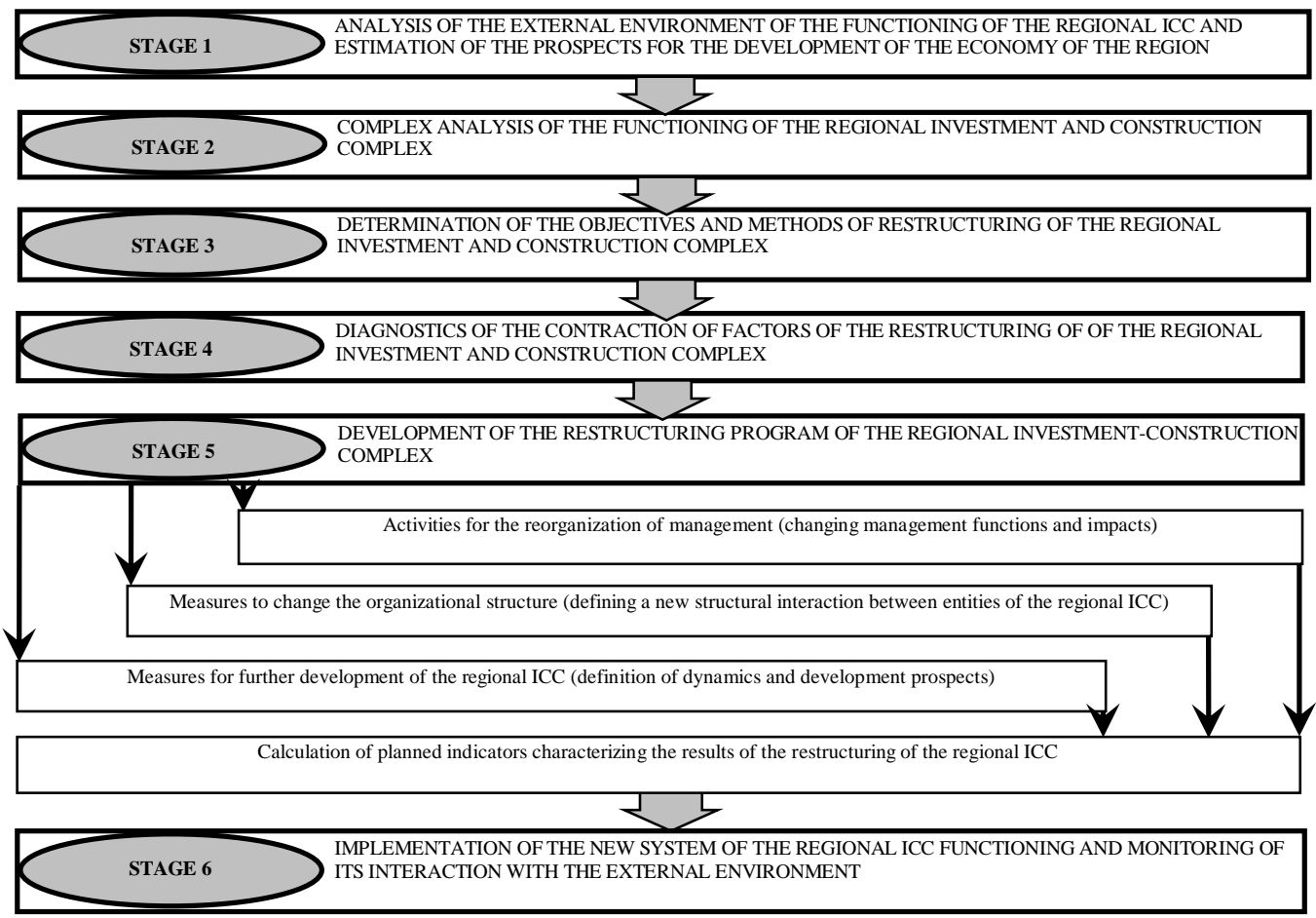

Fig. 1. Stages of the regional ICC restructuring. 


\section{Results}

The substantive aspect of the restructuring process is revealed and its main directions are determined. The essence of the regional ICC is outlined and its composition and structure are specified. The author's definition of the regional investment and construction complex is provided. An assessment of the current state of the ICC in the Irkutsk region has been carried out, and factors hampering its development and adversely affecting the effectiveness of innovative processes in the region identified.

The author has developed the following:

- Organizational and economic mechanism of restructuring, taking into consideration the target functions, strategic and operational tasks of investment and construction activities in the region, and reflection of its impact on various subsystems of the regional ICC;

- Step-by-step model for implementing the reorganization measures in the investment and construction complex within the framework of the proposed mechanism that allows systematizing the process of restructuring;

- Multi-level system of models, which makes it possible to select optimal administrative influences on the regional ICC and the enterprises that make up its structure, as well as the region as a whole, which will finally allow achieving the assigned restructuring goals, taking into account the interests of the actors of different level.

\section{Discussion}

In the current study, discussion is related to the disclosure of the economic essence of the regional investment and construction complex,and determining its composition and structure.

The analysis of scientific publications [21-27] has shown that the essence of the investment and construction complex is differently interpreted by the Russian scientists. It has allowed formulating the author's definition, in accordance with which the regional investment and construction complex is a certain set of industries and organizations of various industries, operating in the field of construction, as well as their management bodies, ensuring the implementation of investment activities on the territory of a particular region in the form of capital investments, that result in the construction products.

There are also discussions about the composition of the regional ICC. Most scientists believe that the investment and construction complex should include four links: construction, industrial, scientific and design and investment ones. However, taking into account the selected way of innovative development of the national economy, in our opinion, the following components should compose the structure of the ICC: investment, construction, industrial and technological, scientific and innovative. Their detailed description is presented in [28]. Considering the dynamism and variety of aspects of the regional economic development, including the investment and construction sector, it is possible to forecast the possibility of further transformations in the composition and structure of regional ICCs.

\section{Conclusion}

This research has allowed developing theoretical knowledge concerning structural transformations in the regional economy on the basis of restructuring of the investment and construction complex.

The practical significance of the results of the scientific research is that the approaches, proposed by the author, the developed restructuring mechanism and the multi-level system 
of models allowed building the integrated model of development of the regional ICC, which makes it possible to take into account the interests of the region's development. The presented recommendations will contribute to the elaboration, adoption and implementation of rational management decisions in the investment and construction industry of the region.

\section{References}

1. V. V. Buzirev, A. D. Kot, SN Strizhkov, Problems of Modern Economics, 2, 176-182 (2003)

2. N. A. Samarskaya, V. A. Dvoianov, A.M. Platonov Anti-crisis management of enterprises of the construction industry (Ekaterinburg, 2012)

3. A. M. Platonov, S. Yu. Pleshkov, Bulletin of the USTU-UPI. Series: Economics and Management, 6, 35-39 (2007)

4. G. V. Khomkalov, E. I. Kelberg, Baikal Research Journal, 8, 3, 7 (2017)

5. E. B. Smirnov, S. Yu. Vetlugin, Herald of INJECON. Series: Economy, 4, 56 (2004)

6. Yu. P. Panibratov, VL Tsapu, Economics and Management of the National Economy, 1, 3-13 (2013)

7. V. V. Buzirev, I. V. Fedoseev, A. D. Kot, Economics, management and investments (A. Miller Library, Chelyabinsk, 2002)

8. N. V. Chepachenko, V. A. Dmitriev, Science and Education: Architecture, Urban Planning and Construction, 241-244 (2010)

9. L. A. Kaverzina, Theory and methodology of restructuring of the regional investment and construction complex in conditions of economic growth (Bratsk, 2008) (in Russian)

10. I. I. Mazur, V. D. Shapiro, S. A. Titov, L. V. Elkina, Restructuring of enterprises and companies (Moscow, 2000)

11. M. S. Motyshina, M. B. Sokolovskaya, Economic cybernetics: system analysis in economics and management, 133-136 (2002)

12. A. N. Asaul, Scientific Works of the Free Economic Society of Russia, 190(1), 253266 (2015)

13. Yu. P. Panibratov, V. I. Pasyada, Economics, 81, 134-138 (2011)

14. M. V. Aristova, Yu. P. Panibratov, Humanitarian Knowledge, 45-52 (2007)

15. K. S. Evtyukova, E. B. Smirnov, Modern Problems of Science and Education, 5, 267 (2012)

16. V. V. Peshkov, Proceedings of the Irkutsk State Technical University, 2-1(30), 148151 (2007)

17. A. N. Asaul, Russian regions in the focus of changes, collection of reports of the $X$ International Conference, 834-851 (2016)

18. V. V. Peshkov, Proceedings of the Irkutsk State Technical University, 1(41), 99-103 (2010)

19. V. V. Buzirev, I. P. Nuzhina, Ecological and economic aspects of investment and construction activities (St. Petersburg, 2012)

20. A. I. Romanova, Proceedings of Kazan State Academy of Architecture and Construction, 1, 70 (2004)

21. I. A. Kuzovleva, Methodological problems of effective functioning and development of the regional investment and construction complex (St. Petersburg, 2001) 
22. V. S. Zubenko, Project management for the regional investment and construction complex (Russian State Library, Moscow, 2003)

23. D. G. Gadelia, Strategic planning of the development of the investment and construction complex of the megapolis (St. Petersburg, 2005)

24. K. V. Ekimova, Formation of integral mechanism of interaction of subjects of investment and construction activity of the region (St. Petersburg, 2006)

25. A. V. Bogoviz, S. V. Lobova, A. N. Alekseev, I. A. Koryagina, T. V. Aleksashina, Advances in Intelligent Systems and Computing, 622, 609-616 (2018)

26. A. I. Romanova, Methodological problems of economic development of the investment and construction complex in the context of a competitive environment (on the example of the Volga Federal District) (Moscow, 2003)

27. A. V. Bogoviz, Y. V. Ragulina, N. V. Sirotkina, Advances in Intelligent Systems and Computing, 622, 597-602 (2018)

28. L. A. Kaverzina, A. V. Mazhitova, Problems of the Social and Economic Development of Siberia, 1(7), 17-25 (2012) 